\title{
Examining a TPB Model towards Intention to Use Biodegradable Drinking Straw Using PLS-SEM
}

\author{
Nadia Nurul Najwa Mohmad Hassan, Juliana Mohd Abdul Kadir, Noreen Noor Abd Aziz \\ Faculty of Business Management, \\ Universiti Teknologi MARA Johor, Segamat, Malaysia
}

nadia666@uitm.edu.my, julia593@uitm.edu.my,noree974@uitm.edu.my Tel: $+6019-7467561$

\begin{abstract}
Intention to use biodegradable drinking straw may be affected by psychological factors. Besides, the impact of factors towards intention may be different between gender. Therefore, this paper analyses the effect of attitude, subjective norm, knowledge, and perceived behavioral control towards the intention to use a biodegradable drinking straw and the moderating effect of gender towards the relationship among variables. The results, which were collected by using online questionnaires and analysed by using PLS-SEM; showed that most of the variables except knowledge had a significant impact on intention to use a biodegradable drinking straw, while gender posits no difference towards the usage intention.
\end{abstract}

Keywords: Intention; Biodegradable Straw; Knowledge; Gender

eISSN: 2398-42870 2020. The Authors. Published for AMER ABRA cE-Bs by e-International Publishing House, Ltd., UK. This is an open access article under the CC BYNC-ND license (http://creativecommons.org/licenses/by-nc-nd/4.0). Peer-review under responsibility of AMER (Association of Malaysian Environment-Behaviour Researchers), ABRA (Association of Behavioural Researchers on Asians) and cE-Bs (Centre for Environment-Behaviour Studies), Faculty of Architecture, Planning \& Surveying, Universiti Teknologi MARA, Malaysia.

DOI: https://doi.org/10.21834/ebpj.v5i15.2428.

\subsection{Introduction}

A plastic drinking straw is commonly used for drinking water and work as an efficient tool in a restaurant and the other service sector. Nevertheless, excessive use results in large quantities of plastic waste, which would harm the environment. The unmanaged plasticbased litter can pollute the ocean and endanger marine species, which causes significant environmental pollutions, economic drawbacks, and health issues.

The utilisation of green products that use natural resources can minimise pollution, whereas the non-biodegradable product is unrecyclable, which gradually harms the environment. A biodegradable drinking straw is an alternative to plastic drinking straw that provides equal usage effectiveness and saves the environment from harm and pollution. Huang (2020) states that a biodegradable drinking straw can be degraded by microorganisms and decay. The production will not excessively consume finite resources, which conserve the energy and protect the environment. An eco-friendly drinking straw can be made from various sources such as paper, bamboo, metal, glass, silicon, and edible straws made from rice, tapioca, and pasta.

Efforts to devise the best plan are worth it if there is a high consciousness about the environment and attitude towards plastic consumption. The government has public outreach campaigns to promote the risks of using a plastic straw and has proposed limiting the use of plastic straw or using biodegradable drinking straw as an option for saving the world. The federal government of Selangor, Malaysia, impose a ban on plastic straws in all eateries starting on July 1, 2019. This action was followed by the Federal Territories of Kuala Lumpur, Putrajaya, and Labuan beginning from January 1, 2020, to all traders and operators of food outlets.

We must educate the younger generation on environmental protection practices, and their attitude towards green products is vital for world sustainability survival. A study done on students' perceptions of environmental issues showed that students have high

eISSN: 2398-4287C 2020. The Authors. Published for AMER ABRA cE-Bs by e-International Publishing House, Ltd., UK. This is an open access article under the CC BYNC-ND license (http://creativecommons.org/licenses/by-nc-nd/4.0/). Peer-review under responsibility of AMER (Association of Malaysian Environment-Behaviour Researchers), ABRA (Association of Behavioural Researchers on Asians) and cE-Bs (Centre for Environment-Behaviour Studies), Faculty of Architecture, Planning \& Surveying, Universiti Teknologi MARA, Malaysia.

DOI: https://doi.org/10.21834/ebpj.v5i15.2428.. 
awareness and knowledge in environmental protection (Osman, Bachok and Ibrahim, 2012) even though the green practices are not shown in their behaviour (Hassan, Rahman, and Abdullah, 2011).

This paper's primary focus is to discover the factors that may affect students' intention to use a biodegradable drinking straw. There are two objectives of this paper. The main aim is to determine the factors that may affect usage intention towards biodegradable drinking straw. The elements are attitude, subjective norm, knowledge and perceived behavioural control which is the component of psychological factors explained in the Theory of Planned Behaviour. The other aim of this study is to test the moderating effect of gender towards the psychological factors and the intention to use a biodegradable drinking straw. To test whether the gender will show the difference in behavioural intention to use biodegradable drinking straw between male and female.

\subsection{Literature Review}

The practice of environmental sustainability is becoming the focus of literature and studies which look at many sides of green lifestyles among the consumers, corporate and the government. Green concept practices in Malaysia is to encourage emphasising international trade involving import and export of green products to compete in the global market while conserving the environment (Rezai, Teng, Mohamed and Shamsudin, 2013). Nagaraju and Thejaswini (2016) stressed that the interest in protecting the environment and sustainable development had increased nowadays among societies.

A study conducted by Ajzen (1991) known as Theory of Planned Behaviour (TPB) is a study on human psychology in the area of marketing, sports management and environmental sustainability. Yadav and Pathak (2017) reported that green purchase practices influenced by intention to buy green products which confirms the TPB theory fully supported consumer intention and behaviour to choose green products and services.

Behavioural intention is when an individual action in a particular manner after making a decision. The intention to use and behaviour in green consumerism has been found positive in a study by Kumar, Manrai and Manrai (2017) which stated higher green intention and led to the higher practice of buying organic products. Arli, Tan, Tjiptono, and Yang (2018) found perceptions towards green products are positively related to consumer's purchase intention.

Subjective norm deals with ethical or moral decision making, which, relates to perceived social pressure which usually affects personal benefit (Tarkiainen and Sundqvist, 2005). Zukin and Maguire (2004) suggested that subjective norms become the factor that encourages consumers to practice green consumption. Besides, Maichum, Parichatnon and Peng (2016) found that social norms encourage environmentally-friendly behaviour in terms of green purchase practices.

The perceived behavioural is influenced by control belief and perceived power. Behaviour control is a predictor in creating people awareness towards recycling behaviour (Ramayah, Lee and Mohamad, 2010). Liobikiené and Juknys (2016) explained that green purchasing behaviour is related to green practice behaviour.

Knowledge of environmental issues results in pro-environmental behaviour (Peattie, 2010), and it gives an impact on purchasing intentions (Rokicka, 2002). Pe'er, Goldman and Yavetz, (2007) suggest that student who studies on the field, which is related to the environment will display environment-oriented attitudes as compared to the other students.

Gender was found to play a role in determining a relationship between intention and green purchase behaviour. The moderating effect of gender was significant on the relationship between environmental concern and attitude towards green purchase behaviour from the Lebanese consumer (Dagner, Itani and Kassar, 2015). Previous research by Venkatesh and Morris (2000) did not support the moderating effect of gender between variables. A study in Malaysia showed that there were no significant differences in environmental attitudes and attitudes on green products between male and female (Chen and Chai, 2010). Regarding the literature mentioned above; this study posits the following research framework.

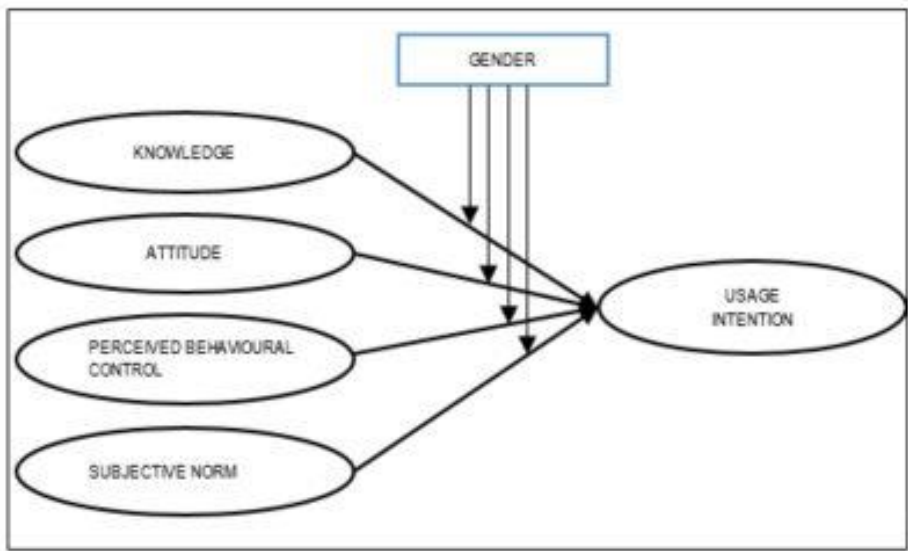

Figure 1: Theoretical framework

\subsection{Methodology}

The research framework indicated that this research focuses on the intention to use a biodegradable drinking straw among students. This study used stratified random sampling to select study participants, and distributed online questionnaire randomly towards 242 students. The study aims to measure the relation between four variables of student's attitude, knowledge, perceived behavioural control 
and subjective norm on their intention to use a biodegradable drinking straw-the questionnaire survey comprised of 21 questions with a five-point Likert scale. The data were coded and analysed by using Smart PLS with the following steps; first, this study examines the model measurement by using confirmatory factor analysis and secondly the structural model measurement was assessed by reviewing the standard path coefficient and $t$-statistics ( $t>1.96)$. Also, this study tested the moderating effect by using multi-group analysis. After that, this study investigated the result of these moderators. This study separated the data-sample into subsamples in this method, and then the same structural model is run for both samples at the same time. To determine reliability and validity, it is then followed by pairwise comparison of path coefficients between the two groups (male vs female), considering the critical ratio for discrepancies between the groups.

\subsection{Findings}

\subsection{Demographic Result}

The survey achieved 100 per cent of response rate comprising students in Universiti Teknologi MARA Segamat Campus, in Johor, Malaysia. Respondent's background tapped in this study was gender, age, academic program and Monthly Allowance. We also asked about their form of monthly expenses and tend to choose, which type of drinking straw. The profile showed that 68.2 per cent of the respondents were female, and the rest (31.8 per cent) were male. They are between the ages of 19-21 years old (65.3 per cent) and 22-24 (31.4 per cent), and the majority of them are degree students (80.2 per cent). From the survey, 58.3 per cent received financial support from parents, and the rest (41.7 per cent) are from study loan. Moreover, it also shows that their monthly allowance ranges below RM500 (56.6 per cent) and RM501-RM1000 (33.5 per cent) and they use to spend the most for snacks and foods ( 80.2 per cent), books, stationery and other study materials (9.1 per cent) and transportation (4.1 per cent). A study revealed that most of the students (95.5 per cent) are more likely to choose a type of plastic of drinking straw instead of wood or stainless steel.

\subsection{Measurement Model}

Fornell and Larcker (1981) recommended that this study measures item reliability, internal accuracy, and average variance extracted (AVE) to assess convergent validity. The loadings for each item was tested using Item Reliability. The extensive item loadings are presented in Table 1. The connection between the items and their respective constructs was demonstrated using the loadings. The results showed that all article greater than 0.7 , which consider as acceptable except for PB6 and U4, which is deemed as adequate if other things have high scores (Chin, 2003). This table also showed that most of the AVE values are above 0.5. Referring to Average Variance Extracted (AVE), the most considerable weight is 0.732 for attitude whilst the lowest is 0.495 for the subjective norm.

Therefore the criterion for a minimum value of 0.7 follows Internal Consistency. Based on the results, this study found that the lowest internal consistency was 0.767 for perceived behavioural control, whilst the highest was 0.916 for attitude. For all constructs, the high internal consistency values ensure the reliability of the measurement model. Therefore, the measurement model satisfied all three necessary criteria and achieved convergent validity. Hence, these results indicate that the items in each construct are highly correlated and reliable.

\begin{tabular}{|c|c|c|c|c|}
\hline Construct & Items & Loading & CR & AVE \\
\hline \multirow[t]{4}{*}{ Attitude } & ATT1 & 0.879 & 0.916 & 0.732 \\
\hline & ATT2 & 0.846 & & \\
\hline & ATT4 & 0.853 & & \\
\hline & ATT5 & 0.844 & & \\
\hline \multirow[t]{4}{*}{ Knowledge } & KN1 & 0.681 & 0.809 & 0.516 \\
\hline & KN3 & 0.714 & & \\
\hline & KN4 & 0.797 & & \\
\hline & KN5 & 0.673 & & \\
\hline \multirow[t]{3}{*}{ Perceived Behavioural Control } & PB1 & 0.895 & 0.767 & 0.516 \\
\hline & PB2 & 0.727 & & \\
\hline & PB6 & 0.522 & & \\
\hline \multirow[t]{5}{*}{ Subjective Norm } & SN1 & 0.79 & 0.829 & 0.495 \\
\hline & SN2 & 0.761 & & \\
\hline & SN3 & 0.724 & & \\
\hline & SN4 & 0.603 & & \\
\hline & SN5 & 0.618 & & \\
\hline \multirow[t]{2}{*}{ Usage Intention } & U1 & 0.888 & 0.85 & 0.594 \\
\hline & U2 & 0.751 & & \\
\hline
\end{tabular}




\begin{tabular}{cc}
\hline U4 & 0.534 \\
\hline U5 & 0.86 \\
\hline
\end{tabular}

Due to low loadings, this study deleted ATT3, KN2, PB3, PB4, PB5 and U3.

The study assessed the first criterion of discriminant validity by calculating the square root of the average variance extracted (AVE). This value is correlated between constructs. The square roots of the AVE were determined to achieve the discriminant validity criterion and depicted in the main diagonal of Table 2. The off-diagonal components reflect the relationships between the latent variables. Barclay, Higgins, and Thompson (1995) defined that when the square root of a construct's AVE is more extensive than its correlation with other constructs, discriminant validity is achieved. It is verified in Table 2 that the discriminant validity was achieved.

\begin{tabular}{cccccc}
\multicolumn{7}{c}{ Table 2. Discriminant Validity } & & & SN & U \\
\hline Construct & A & K & PB & & \\
\hline Attitude (A) & 0.769 & & & & \\
\hline Knowledge (K) & 0.385 & 0.652 & & & \\
\hline Perceived Behavioural Control (PB) & 0.553 & 0.453 & 0.558 & & \\
\hline Subjective Norm (SN) & 0.61 & 0.444 & 0.619 & 0.703 & \\
\hline Usage Intention (U) & 0.642 & 0.321 & 0.597 & 0.617 & 0.692 \\
\hline
\end{tabular}

The cross-loading matrix explained that all items on the construct they measured are loaded higher than on any other construct in the model. The two conditions of discriminant validity were thus satisfied. The assumption is that all the reflective structures are different from each other in the measurement model.

\subsection{Result of Hypothesis Testing}

Table 3. Hypothesis Testing

\begin{tabular}{cccrc}
\hline Hypothesis & Relationship & $\begin{array}{c}\text { Standard Path } \\
\text { Coefficient }\end{array}$ & t-value & Results \\
\hline$H_{1}$ & Attitude - Usage Intention & 0.062 & 5.793 & Supported \\
\hline$H_{2}$ & Knowledge - Usage Intention & 0.047 & 1.058 & Not Supported \\
\hline$H_{3}$ & Perceived Behaviour Control - Usage Intention & 0.057 & 4.585 & 3.451 \\
\hline$H_{4}$ & Subjective Norm - Usage Intention & 0.075 & Supported & Supported \\
\hline
\end{tabular}

Note: ${ }^{*} p<0.05$ or ${ }^{* *} p<0.01$

The hypothesis testing for the main model was presented in Table 3. The standardised path coefficient indicates whether the relationship's course is positive or negative, while the t-value evaluates whether or not this relationship is significant. $\mathrm{H}_{1}, \mathrm{H}_{2}, \mathrm{H}_{3}$ and $\mathrm{H}_{4}$ examined the influence of attitude, knowledge, perceived behaviour control and subjective norm on intention, respectively. This table showed that all four variables for standard path coefficients were positive. More specifically, for $\mathrm{H}_{1}$, the standardised path coefficient is 0.062 , whilst the t-value is 5.793 . This study accepts the result; which t-value is higher than $1.96 . \mathrm{H}_{2}$ explained the standard path coefficient is 0.047 whilst $t$-value is 1.058 . This study did not accept the result; which t-value is lower than 1. 96. $\mathrm{H}_{3}$ explained the standard path coefficient is 0.057 whilst $t$-value is 4.585 . The result was accepted at $t>1.96 . \mathrm{H}_{4}$ explained the standard path coefficient is 0.075 whilst $t$-value is 3.451 . The result was accepted at $t>1.96$. In conclusion, three $\left(\mathrm{H}_{1}, \mathrm{H}_{3}\right.$, and $\left.\mathrm{H}_{4}\right)$ of the hypotheses were statistically significant.

\subsection{Discussion}

The findings of this study are the attitude, perceived behavioural control and the subjective norm will influence the consumer to use a biodegradable drinking straw. The results showed that the attitude, subjective norm and perceived behavioural of the students had a significant impact on their intention towards biodegradable drinking straw. Firstly, if the consumer has a positive attitude towards biodegradable drinking straw, they will choose the product and continue to use the product. Secondly, perceived behavioural control has a positive impact, which proves that, if consumer belief that they can increase the use of green products, they can help to conserve the environment. The people will act based on their intention and perceptions of control over the behaviour (Kiriakidis, 2017). Third, the subjective norm has a positive effect on intention showed that if the societies support the usage of biodegradable drinking straw; this will enhance the number of consumers who will choose the product. Fourth, knowledge has not impacted usage intention suggests that student knowledge on environmental protection will not influence their intention to use a biodegradable drinking straw.

Last but not least, gender did not moderate the relationship between variables (attitude, subjective norm, perceived behavioural control, knowledge) and usage intention. Our findings show that with gender, the strength of ties between the variables does not change. It 
implies that no matter what gender a person belongs to, there is no effect on the usage intention using a biodegradable drinking straw. It showed that from the findings, previous research by Venkatesh and Morris (2000) did not support the moderating effect between variables. Chen and Chai (2010) also found no significant differences between male and female on environmental attitudes and green products.

\subsection{Conclusion and Recommendations}

This study tested the relationship between attitude, subjective norms, knowledge and perceived behavioural control towards behavioural intention to use biodegradable drinking straw among students in Malaysia. This study tested the intention of whether gender will play the role of the moderating effect. Students selected as respondents are below 24 years' old which pursuing studies in many different courses in Universiti Teknologi MARA, Malaysia.

This study found that the attitudes, subjective norms and perceived behavioural control has a positive relationship with the intention to use a biodegradable drinking straw. However, knowledge is not significant in explaining the usage intention. The attitude was the most critical factor to develop usage intention towards using a biodegradable drinking straw which implies students has created a positive attitude towards the environment. However, the green practices are still at a moderate level because students tend to choose to use plastic drinking straw compared to reusable wooden or stainless-steel straws. The role of gender as the moderating variable was insignificant, which implies no difference between male and females in intention to use a biodegradable drinking straw.

The implications of this study showed the majority of student choose plastic straw rather than a biodegradable drinking straw. We assume this is because plastic straw is conveniently available and still supplied by the foodservice providers. Therefore, food service providers should encourage consumers to start using green products by providing biodegradable drinking straw. This also means the high level of adherence food service providers to follow the rules and regulation set by the government will help to promote environmental conservation. Other than that, campaigns to encourage the use of biodegradable drinking straw is required by stressing the effective and efficient use of biodegradable drinking straw in terms of durability, ease of purchase and the cost to purchase the to enhance the user preference and purchase decision among consumers.

Therefore, the rules and regulation set by the government should be applied not only to food traders but also to a manufacturing company which supply products related to general use in food industry such as food packaging, disposable utensils, plastic container and so on. If the production of non-biodegradable plastic is reduced, the usage on the product will be limited among the consumer. This will encourage the consumer to switch usage alternative to biodegradable products.

There are some limitations to the method of this study. Firstly, the responses were collected from university students. Therefore, the findings only support the behaviour of young consumers and not consumers of every age group. Secondly, this study uses a biodegradable drinking straw as the main product to relate the usage intention towards environmentally friendly and biodegradable products, which exclude other environmentally friendly products which are non-biodegradable such as stainless-steel drinking straw. Last but not least, this study only limited to predictors used is the TPB model, which did not include all factors that may influence students to use a biodegradable drinking straw. Last but not least, this study focusses solely on biodegradable applications which relate to environment preservation topic but did not touch on the waste management, recycling practices and other green practices.

The contributions of this study are, it will be a guideline for scholars and policymakers to prepare for more strategies on the use of a biodegradable straw. Besides, this research contributes to the hypothesis by presenting empirical evidence of the relationship between attitude toward the environment, subjective norm, and perceived behavioural control and gender on young educated consumer's intentions using a biodegradable drinking straw.

The extension study is required to have socio-economic factors which may help the policymakers to encourage different demographic background for green practices lifestyle and cultures. Future research should include an emphasis on the psychology of consumers in making usage and purchase decision on biodegradable products. Many other relevant factors that may become the crucial predictors may consist of various other personal characteristics and situational factors. The findings of this study only confined to consumers in Malaysia; thus, future research should consider differences in lifestyle and cultures, the number of campaigns on environmental preservation and environmental concerns among societies is at the early stage of implementation. Hence, any future research conducted in other countries should adjust for differences in efforts on environmental problems due to some unique factors.

\section{Paper Contribution to Related Field of Study}

This research contributes to filling the gap in the existing study on the intention to use a biodegradable straw among students in Malaysia.

\section{Acknowledgements}

We want to thank the survey respondents for taking their time to answer the questionnaire and the panel of reviewers for their valuable comments. 


\section{Paper Contribution to Related Field of Study}

This research contributes to filling the gap in the existing study on the intention to use a biodegradable straw among students in Malaysia by extending research on the use of disposable biodegradable products. This study focusing on the behavioural factors that will influence consumer in Malaysia to choose biodegradable products. This paper also proven the importance of assessing consumer behaviour from perspective of consumer psychology in choosing products to encourage them to become environment conscious consumers.

\section{References}

Ajzen, I. (1991). The Theory of Planned Behaviour. Organisational Behaviour and Human Decision Processes, 50, 179-211.

Arli, D., Tan, L. P., Tjiptono, F., \& Yang, L. (2018). Exploring consumers' purchase intention towards green products in an emerging market: The role of consumers' perceived readiness. International journal of consumer studies, 42(4), 389-401.

Barclay, D. \& Thompson, R. \& Higgins, C. (1995). The Partial Least Squares (PLS) Approach to Causal Modeling: Personal Computer Use as an Illustration. Technology Studies. 2.

Chelvi, S. T. (2020). 'Green' straws. The Sun Daily. https://www.thesundaily.my/style-life/feature/green-straws-BM1970517

Chen, T. B. and Chai, L. T. (2010). Attitude towards the Environment and Green Products: Consumers' Perspective. Management Science and Engineering, 4 (2), pp. $27-39$

Chin, W.W. (2003), "A permutation procedure for multi-group comparison of PLS models", in Vilares, M., Tenenhaus, M., Coelho, P., Esposito Vinzi, V. and Morineau, A. (Eds), PLS and Related Methods, Decisia, Lisbon, pp. 33-43.

Dagher, G., Itani, O., \& Kassar, A. N. (2015). The Impact of Environment Concern and Attitude on Green Purchasing Behavior: Gender as The Moderator. Contemporary Management Research, 11(2). https://doi.org/10.7903/cmr.13625

Fornell, C. and Larcker, D.F. (1981). Evaluating Structural Equation Models with Unobservable Variables and Measurement Error. The University of Michigan, 18 (1), pp. $39-50$.

Hassan, A., Rahman, N. A., \& Abdullah, S. I. S. S. (2011). The level of environmental knowledge, awareness, attitudes and practices among UKM students. University Kebangsaan, Malaysia.

Huang, C. C. (2020), Biodegradable Drinking Straw.

Kiriakidis S. (2017) Perceived Behavioural Control in the Theory of Planned Behaviour: Variability of Conceptualisation and Operationalisation and Implications for Measurement. In: Kavoura A., Sakas D., Tomaras P. (eds) Strategic Innovative Marketing. Springer Proceedings in Business and Economics. Springer, Cham. https://doi.org/10.1007/978-3-319-33865-1_25

Kumar, B., Manrai, A. K., \& Manrai, L. A. (2017). Purchasing behaviour for environmentally sustainable products: A conceptual framework and empirical study. Journal of Retailing and Consumer Services, 34, 1-9.

Liobikienè, G., \& Juknys, R. (2016). The role of values, environmental risk perception, awareness of consequences, and willingness to assume responsibility for environmentally-friendly behaviour: the Lithuanian case. Journal of Cleaner Production, 112, 3413-3422.

Maichum, K., Parichatnon, S., \& Peng, K. C. (2016). Application of the extended theory of planned behaviour model to investigate the purchase intention of green products among Thai consumers. Sustainability, 8(10), 1077.

Nagaraju, B., \& Thejaswini, H. D. (2016). A Study on Consumer Attitude towards Eco-Friendly FMCG Products with Reference to Hubli City in Karnataka. IOSR Journal of Business and Management (IOSR-JBM) Vol, 18(11), 58-63.

Osman, M.M.; Bachok, S.; Ibrahim, A.N. (2012). The Level of Awareness towards Environmental Issues and Concern among Students in Tertiary Level: Case Study of Universities Students in Kuala Lumpur and Klang Valley of Malaysia. In Readers of Environmental Planning in Malaysia; IIUM Press: Batu Caves, Malaysia, 59-73.

Peattie, K. (2010). Green consumption: behaviour and norms. Annual review of environment and resources, 35.

Pe'er, S., Goldman, D., \& Yavetz, B. (2007). Environmental literacy in teacher training: Attitudes, knowledge, and environmental behaviour of beginning students. The Journal of Environmental Education, 39(1), 45-59.

Ramayah, T., Lee, J. W. C., \& Mohamad, O. (2010). Green product purchase intention: Some insights from a developing country. Resources, conservation and recycling, 54(12), 1419-1427.

Rezai, G., Teng, P. K., Mohamed, Z., \& Shamsudin, M. N. (2013). Going green: Survey of perceptions and intentions among Malaysian consumers. International Business and Management, 6(1), 104-112.

Rokicka, E. (2002). Attitudes toward the natural environment: A study of local community dwellers. International Journal of Sociology, 32(3), 78-90.

Tarkiainen, A., \& Sundqvist, S. (2005). Subjective norms, attitudes and intentions of Finnish consumers in buying organic food. British Food Journal, 107(11), 808-822.

Yadav, R., \& Pathak, G. S. (2016). Young consumers' intention towards buying green products in a developing nation: Extending the theory of planned behaviour. Journal of Cleaner Production, 135, 732-739.

Zukin, S., \& Maguire, J. S. (2004). Consumers and consumption. Annual Review of Sociology, 30, 173-197. 